\title{
Periprostetik enfeksiyonda hastaya ait risk faktörleri
}

\author{
Patient-related risk factors for periprosthetic joint infection
}

\author{
Ömer Faruk Erkoçak
}

Selçuk Üniversitesi Tıp Fakültesi Ortopedi ve Travmatoloji Anabilim Dalı, Konya

\begin{abstract}
Periprostetik eklem enfeksiyonu, total eklem artroplastisi sonrası ciddi hasta morbiditesine neden olan yıkıcı bir komplikasyondur. Korunma, bu can sıkıcı komplikasyonla başa çıkmadaki en önemli stratejidir ve korumaya hastaya ait risk faktörlerini belirlemekle başlanmalıdır. Obezite, malnutrisyon, hiperglisemi ve kontrolsüz diyabet, romatoid artrit, cerrahi öncesi anemi, kardiyovasküler hastalıklar, kronik böbrek yetmezliği, sigara, alkol bağımlılığı ve depresyon gibi hastaya ait risk faktörleri incelenmeli ve cerrahi öncesi optimize edilmelidir.
\end{abstract}

Anahtar sözcükler: total eklem artroplastisi; prostetik enfeksiyon; risk faktörleri
Periprosthetic joint infection is a devastating complication after total joint arthroplasty associated with substantial patient morbidity. Prevention is the most important strategy to deal with this disabling complication, and should begin with identifying patient-related risk factors. Patient-related risk factors such as morbid obesity, malnutrition, hyperglycemia, uncontrolled diabetes mellitus, rheumatoid arthritis, preoperative anemia, cardiovascular disorders, chronic renal failure, smoking, alcohol abuse, and depression should be evaluated and optimized prior to surgery.

Key words: total joint artoplasty; prosthetic infection; risk factors
P eriprostetik enfeksiyon (PPE), total eklem replasmanı sonrası en korkulan ve tedavisi en güç komplikasyonlardan biridir. Artroplastide cerrahi sırasında alınan tedbirler ve tedavideki gelişmeler sonucunda son 50 yılda enfeksiyon oranlarında belirgin azalma kaydedilmesine rağmen, giderek artan oranlarda eklem artroplastisi uygulanması nedeniyle kümülatif sayı gün geçtikçe artmaktadır. PPE, literatürde total diz protezi revizyonunun en sık ${ }^{[1]}$, total kalça protez revizyonunun ise üçüncü en sık nedeni olarak bildirilmiştir ${ }^{[2]}$.

Protez enfeksiyonlarından korunma, geliştikten sonraki tedavi sürecinden çok daha az yorucu ve daha az masraflı bir süreçtir. PPE'ye neden olan risk faktörlerinin bilinmesi ve gerekli önlemlerin alınması PPE insidansının azalmasını sağlar. Bu bağlamda, konakçı direncinin arttırılması için yüksek riskli hastaların tanımlanması son derece önemlidir. Çünkü konakçının mevcut genel sağlık durumunun, oluşacak cerrahi sonrası komplikasyonlarla direkt ilişkisi birçok çalışmada net olarak gösterilmiştir. ${ }^{[3-5]}$ Literatürdeki çalışmalarda konakçıya ait birçok risk faktörü tanımlanmakla beraber; obezite, romatoid artrit (RA), steroid kullanımı, diabetes mellitus (DM), malnütrisyon, malignite, pulmoner, kardiyovasküler ve renal yetmezlik öyküsünün olması, sigara kullanımı, daha önceden artroplasti cerrahisi ve septik artrit geçirmiş olması en önemli risk faktörleri olarak belirtilmiştir. ${ }^{[6]} \mathrm{Bu}$ arada, ileri yaş, ırk ve cinsiyet PPE üzerine etkileri kesin olarak kanıtlanamamış ve üzerinde tam bir fikir birliğine varılamamış faktörlerdir.

Uluslararası konsensus toplantısında (ICM, 2013, Philadelphia, USA) aynı eklemdeki daha önceki cerrahi, kontrolsüz diyabet (glukoz $>200 \mathrm{mg} / \mathrm{dl}$ veya HbA1C >\%7) malnütrisyon, morbid obezite (VKi $>40 \mathrm{~kg} / \mathrm{m}^{2}$ ), kronik renal yetmezliği, aktif KC hastalığı, aşırı sigara kullanımı (>1 paket/gün), alkol bağımlılığı (>40 ünite/hafta), madde bağımlılığı, uzamış cerrahi sonrası hastanede kalış, posttravmatik artrit, inflamatuvar artropati, erkek cinsiyet ve ciddi immünsupresyon PPE riskini arttırabilecek faktörler olarak bildirilmiştir. ${ }^{[7]}$

- Illetişim adresi: Doç. Dr. Ömer Faruk Erkoçak, Selçuk Üniversitesi Tıp Fakültesi Ortopedi ve Travmatoloji Anabilim Dalı, Konya Tel: 0332 - 2415000 e-posta: farukerkocak@gmail.com

- Geliștarihi: 1 Mart $2016 \quad$ Kabul tarihi: 1 Mart 2016 


\section{DEMOGRAFIK FAKTÖRLER}

\section{Yaş}

Yaşın total diz artroplastisi (TDA) ve total kalça artroplastisi (TKA) sonrası enfeksiyon gelişimi için bir risk faktörü olup olmadığı halen tam olarak aydınlatılamamıştır. Bu konuda literatür incelendiğinde ileri hasta yaşının PPE gelişimi için bir risk faktörü olduğunu öne süren çalışmalar mevcuttur. ${ }^{\left[{ }^{8,9]}\right.} \mathrm{Bu}$ görüşü destekleyen çalışmalarda özellikle 80 yaş üzeri hastaların hem hemiartroplasti hem de primer TKA sonrası yara yeri enfeksiyonu ve revizyon açısından yüksek riske sahip oldukları belirtilmiştir. ${ }^{10,11]}$ PPE gelişiminde hasta yaşını risk faktörü olarak gören çalışmalar bu konuda bimodal bir dağılım elde etmişler, 55 yaşın altındaki ve 75 yaşın üzerindeki hastaların enfeksiyon açısından daha riskli olduğu sonucuna varmışlardır. ${ }^{[8,9]}$ Genç hastalardaki bu yüksek riskin onları erken yaşta eklem replasmanına götüren sebepten veya eşlik eden diğer hastalıklardan kaynaklanabileceği düşünülmüştür. ${ }^{[10]}$

Bununla birlikte yaş ile artroplasti sonrası enfeksiyon arasında bir ilişki olmadığını veya eşlik eden diğer faktörler elimine edildiğinde yaşın kendi başına risk oluşturmayacağını belirten yayınlar da mevcuttur. ${ }^{[5,12,13]}$

\section{Cinsiyet}

Seks hormonlarının ve seks kromozomu genetik içeriğinin insanlarda doğal ve adaptif immün sistemi modüle edebildiğ ${ }^{[14]}$ ve birçok kas iskelet sistemi hastalığının erkek ve kadınlarda farklı prevalansta ortaya çıkabildiği bilinen bir gerçektir. Buna bağlı olarak erkek ve kadınların patojenik bakterilere farklı immün cevaplar oluşturabilmeleri bazı enfeksiyonların prevalansının her iki cinsiyet arasında farklılık göstermesini açıklayabilir. Artroplasti sonrası PPE oranının her iki cinsiyet arasında gösterdiği dağılımı araştıran birçok çalışmada erkeklerin kadınlara oranla daha yüksek riske sahip olduğu tespit edilmiştir. ${ }^{[1,2,5,8,9,11-13,15-17]}$ Bunun her iki cinsiyetteki cilt ve cilt altı bölgedeki $\mathrm{pH}$ değerlerinin, sebum indüksiyonunun, cilt kalınlığının, yağ dağılımının ve metabolizma hızlarının farklılığına bağlı olabileceği öngörülmüştür. ${ }^{[18-20]}$ Ayrıca cilt üzerindeki mikrobiyal floranın erkeklerde ve kadınlarda farklı olduğu, erkeklerde persistan S.aureus taşıyıcılı̆̆ına eğilimin daha fazla olduğu öne sürülmüsştür. ${ }^{[21]}$ Yine ilginç şekilde PPE riskinin obez kadınlarda obez olmayanlara göre 16 kat arttığını tespit eden başka bir çalışmada yazarlar erkeklerde obezitenin böyle bir risk getirmediği belirtmişlerdir. ${ }^{[16]}$

Diğer taraftan PPE riski ile cinsiyet arasında ilişki olmadığını öne süren çalışmalar da mevcuttur. ${ }^{[10,11,22-25]}$
Literatürdeki bu tür çelişkili sonuçlar nedeniyle bazı yazarlar cinsiyetin kendi başına PPE için bağımsız bir risk faktörü olmadığını, muhtemelen henüz üzerinde çalışıımamış bazı risk faktörlerinin cinsiyete atfedilmiş olabileceğini belirtmişlerdir. ${ }^{[26,27]}$

\section{Obezite}

Obezitenin PPE için bağımsız bir risk faktörü olduğu literatürdeki birçok çalışmada ortaya konmuştur. ${ }^{[28-31]}$ Obeziteye eşlik eden iskemik kalp hastalığı, hipertansiyon, Tip 2 DM, hiperkolesterolemi gibi komorbiditelerin veya bunların bir arada olduğu metabolik sendrom gibi durumların cerrahi sonrası iyileşmeyi yavaşlattığı ve cerrahi sırasında komplikasyonları arttırdığı bilinmektedir. ${ }^{[32,33]}$ Vücut kitle indeksinin (VKI) $35 \mathrm{~kg} / \mathrm{m}^{2}$ 'yi geçtiği durumlarda cerrahi saha enfeksiyonunun total diz protezi sonrası yaklaşık 6,5 kat, total kalça protezi sonrası yaklaşık dört kat arttığı belirtilmiştir. ${ }^{[34]}$ Özellikle VKİ'nin $40 \mathrm{~kg} / \mathrm{m}^{2}$ 'nin üzerine çıktığı durumlarda bu riskin daha da artacağı, 50 $\mathrm{kg} / \mathrm{m}^{2}$ 'nin üzerine geçtiğinde ise riskin yaklaşık $21 \mathrm{~kat}$ daha fazla olacağı bildirilmiştir. ${ }^{[29]}$ Aslında bu risklerin çoğunun cerrahi yara iyileşmesindeki problemlerden kaynaklandığı düşünülmektedir. ${ }^{[35,36]}$ Çünkü bu hastalarda insizyon sahasındaki artmış yüzey geriliminin yara iyileşmesini olumsuz etkilediği düşünülmektedir. Ayrıca cerrahi sırasında geniş disseksiyon gerekliliği ve uzamış cerrahi zamanı cerrahi sonrası daha fazla hematom ve seroma oluşumuna veya uzamış yara drenajına neden olmaktadır. ${ }^{[37]}$ Diğer taraftan, oldukça kalın ve zayıf vaskülarize olmuş cilt altı yağ dokusunun insizyon sahasında düşük $\mathrm{O}_{2}$ basıncına yol açması da yara iyileşmesini olumsuz yönde etkiler. $^{[38]}$ Obezitenin nazal S.aureus taşıyıcılığına yol açtığını bildiren yayınlar da olmuştur. ${ }^{[21]}$ Son olarak bu hastalarda profilaktik antibiyotik dozunun kilo ile orantılı olmayan şekilde yetersiz uygulanmasının da, PPE riski için potansiyel oluşturabileceği bildirilmiştir. [39] Obezitenin PPE için risk faktörü olmadığını belirten az sayıda çalışma da mevcuttur. ${ }^{[6]}$

Diğer taraftan düşük VKi'ye $\left(<25 \mathrm{~kg} / \mathrm{m}^{2}\right)$ sahip olanların da vücut besin rezervi ve gelişebilecek immünsupresyon nedeniyle PPE açısından yüksek riske sahip olacakları belirtilmiştir. ${ }^{[40]}$

\section{Sosyoekonomik Durum}

Sosyoekonomik durum PPE gelişme riski açısından kişiyi dolaylı olarak olumlu ya da olumsuz etkileyebilecek kompleks bir faktördür. ${ }^{[1,2,9,22]}$ Teorik olarak düşük sosyoekonomik duruma zayıf beslenme alışkanlıklarına ve eşlik eden morbiditelerin yeterince takip ve tedavi edilememesine bağlı olarak konakçının genel sağlık durumunu kötüleştirebilir ve bu yüzden PPE riskini 
arttırabilir. Ancak her iki durum da PPE için ayrı potansiyel risk faktörüdür ve sosyoekonomik durumdan bağımsız ayrı başlıklar halinde incelenir. Dahası; ırk, kültür gibi faktörlerin de bu noktada etkili olabileceği göz önünde bulundurulduğunda, sosyoekonomik durum ile PPE gelişme riski arasındaki kompleks bağlantıyı çözmenin kolay olmadığı anlaşıır.

\section{Sigara}

Yol açtığı kronik obstrüktif akciğer hastalığı, ateroskleroz ve diğer birçok sistemik problemin etkilerinin karışması nedeniyle, sigara ile PPE arasındaki ilişkiyi net olarak ortaya koymak zordur. Ancak sigaranın cerrahi yara etrafındaki kollajen sentez ve matürasyonu engellediği bilinmektedir. ${ }^{[41]}$ Bir başka çalışmada ise sigaranın spinal füzyon cerrahisi sonrası kemik kaynamasını geciktirdiği bildirilmiştir. ${ }^{[42]}$

Doku iyileşmesi için yeterli miktarda oksijenin sahaya ulaşması şarttır. ${ }^{[43]}$ Sigara nedeniyle oluşan yara hipoksisi miroorganizmalara karşı nötrofil defans fonksiyonunu olumsuz etkileyerek enfeksiyona predispozisyon oluşturur. ${ }^{[38]}$ Sigara, farklı mekanizmalar ile doku hipoksisi oluşturur. Katekolamin deşarjına neden olarak mikrovasküler vazospazma ve subkutan hipoperfüzyona yol açar; aynı zamanda platelet agregasyonuna ve mikrotrombüs oluşumuna neden olur. Ayrıca, inhale edilen $\mathrm{CO}_{2}$ 'nin hemoglobine yarışmalı olarak bağlanması karboksihemoglobine yol açarak periferik dokulara yeterli $\mathrm{O}_{2}$ taşınmasını engeller. Bu yüzden elektif bir artroplasti ameliyatından 6-8 hafta önce sigaranın bırakılmasının cerrahi sonrası erken enfeksiyona yol açabilecek yara iyileşme problemlerini azaltacağı bildirilmiştir. ${ }^{[44,45]}$

Her ne kadar sigaranın erken cerrahi sonrası dönem üzerine zararlı etkileri net olarak gösterilmişse de, diz ve kalça artroplastisi yapılmış hastaların uzun dönem takiplerinde, sigaranın PPE'ye yol açtı̆̆ına dair bir kanıta rastlanmamıştır. ${ }^{[30,46]}$

\section{Alkol Bağımlılı̆ğ}

Haftada 40 üniteden fazla alkol alımının kanama ve enfeksiyon gibi cerrahi sonrası komplikasyonları arttırdığı bildirilmiştir ${ }^{[47-49]}$ Alkole bağlı gelişen cerrahi sonrası komplikasyonların alkolün immündeprese edici etkisi nedeniyle ortaya çıktığı düşünülmektedir. ${ }^{[47]}$ Günde 2-3 bardak alkol alımının immün cevabın fonksiyonunu bozduğu ve gecikmiş tip hipersensitiviteyi suprese ettiği tespit edilmiştir. ${ }^{[50]}$

Alkole ara vermenin elektif artroplasti sonrası PPE riskini azalttığı gösterilmemişse de, birçok çalışmada belli süre alkolden uzak durmanın cerrahi sonrası morbiditeyi azaltacağı belirtilmiştir. ${ }^{[50,51]}$ iki-üç haftalık aranın gecikmiş tip hipersensitiviteyi iyileştirdiği, sekiz hafta sonunda ise ancak normale döndüğü yapılan çalışmalarda gösterilmiştir. Alkoliklerde immün sistem 2-6 haftalık aradan sonra düzelmekte ${ }^{[52]}$, yara iyileşmesi ise 3-4 haftalık aradan sonra normale dönmektedir ${ }^{[53]}$. Bu bilgilere dayanarak artroplasti hastalarında alkole bağlı fizyolojik anormalliklerin düzelmesi ve PPE riskinin normale dönmesi için, alkol kullanımının en az dört hafta önceden bırakılması uygun yaklaşım olacaktır. ${ }^{[51,54]}$

\section{KOMORBIDITELER VE KOMORBIDITE INDEKSLERi}

Artroplasti uygulanacak hastanın genel sağlığı ile cerrahi sonrası komplikasyonlar arasında direkt bağlantı olduğu önceki çalışmalarda gösterilmiştir. Örneğin; ASA skorunun ikinin üzerinde olması, kontrolsüz diyabet ve romatoid artrit bulunması PPE riskinde ciddi artışa neden olur. ${ }^{[3,4,5,26]}$ Elektif artroplasti hastaları genellikle suboptimal sağlık şartlarına sahiptirler. Artroplasti uygulanan hastalardaki mevcut komorbiditeler PPE gelişiminde kümülatif risk oluşturmaktadır. ${ }^{[29,55,56]}$ Her bir komorbiditenin PPE gelişimine ilave $\% 0,35$ 'lik risk kazandırdığı bildirilmiştir. ${ }^{[57]}$

Komorbiditelerin kişiye etkilerini değerlendirmek için çeşitli indeksler tanımlanmıştır. Bunlardan birisi Charlson komorbidite indeksidir. ${ }^{[58]}$ Başlangıçta sadece cerrahi sonrası bir yıllık ölüm oranını öngörebilmek için planlanan bir indeks olsa da, sonraları cerrahi sonrası komplikasyonlar açısından komorbiditelerin derecelendirilmesi için de kullanılır hale gelmiştir. Bu indekse göre komorbid hastalıklar ciddiyeti ölçüsünde puanlanmıştır. (Tablo 1 ve 2) Komorbiditelere hafif hastalık durumundan ciddi hastalık durumuna doğru sırasıyla 1, 2, 3, 4 şeklinde puan verilmiş ve komorbid hastalıkların puanları toplanarak elde edilen ağırıklı puana göre de komorbidite derecelendirmesi yapılmıştır. Kırk yaşın üzerindeki hastalar her bir dekad için 1 puan daha eklenerek hesaplanmıştır. Bu derecelendirmeye göre hastalar $0,1-2,3-4,5$ ve üzeri olmak üzere, dört dereceye ayrılarak incelenmiştir. Charlson komorbidite indeksine göre üç veya daha fazla puana sahip hastalar cerrahi sonrası enfeksiyon açısından daha riskli bulunmuşlardır. ${ }^{[22,59]}$

ASA (American Society of Anesthesiologists) Fiziksel Durum Klasifikasyon Skoru, cerrahi öncesi genel sağlık durumunu mevcut komorbiditelerin ciddiyetine dayanarak nonspesifik bir şekilde skorlamaya yarar. Yüksek ASA skorlarının PPE ile ilişkili olduğu birçok çalışmada bildirilmiştir. ${ }^{[3,10]}$ Diğer taraftan ASA skorunun PPE açısından güvenirlilik ve geçerliliğinin sorgulanması gerektiğini düşünenler de mevcuttur. ${ }^{[60,61]}$ 
$\mathrm{Bu}$ konuda yararlı olabilecek diğer bir indeks ise NNIS (National Nosocomial Infections Surveillance System) indeksidir. Cerrahi sonrası cerrahi alanlarda enfeksiyon riskini belirlemek ve klinikler arası enfeksiyon oranlarını karşılaştırabilmek amacıyla geliştirilmiştir. ${ }^{\left[{ }^{[2]}\right]}$ Üç komponenti ve $0-4$ arası skorlaması vardır. Bu indeks yaranın kontaminasyon derecesine ait sınıflamaya ilaveten, ASA Fiziksel Durum Klasifikasyon Skoru'nu ve ameliyat süresini içermektedir. Kontamine veya kirli yara varlığında bir puan, ASA skoru 3-5 arasında ise bir puan ve ameliyat süresi 75 persentilin ( $T$ noktası) üzerine çıkarsa bir puan verilerek değerlendirilir. Bazı çalışmalar NNIS indeksinin cerrahi sonrası yara yeri enfeksiyonu için iyi bir belirleyici olduğunu, aynı zamanda PPE içinde yararlı olabilecek bir indeks olduğunu bildirmişlerdir. ${ }^{[6,59,62]}$

\section{SPESIFIK KOMORBIDITELER}

\section{Diabetes Mellitus ve Hiperglisemi}

Kontrolsüz diyabet ve hipergliseminin PPE riskini arttırdığı bilinmektedir. ${ }^{[26,28,29,55,63]}$ Total eklem protezi yapılan hastalarda cerrahi öncesi serum glukoz seviyesinin diğer faktörlerden bağımsız olarak morbidite ve mortaliteyi etkilediği tespit edilmiştir. ${ }^{[64]}$ Diğer bazı çalışmalarda, diyabetik hastaların total eklem protezi sonrası PPE açısından dört kat daha fazla riske sahip oldukları gösterilmiştir. ${ }^{[57,65]}$ Hiperglisemi vasküler permeabiliteyi, oksijenasyonu, redoks tepkimelerini, nötrofil bağlanmasını, kemotaksisi, fagositozu, antikor etkinliğini ve hücre içi bakterisidal aktiviteyi olumsuz etkileyerek, bakterilere karşı vücut savunmasını zayıflatmaktadır. Kan glukoz seviyesi $250 \mathrm{mg} / \mathrm{dl}$ üzerine çıktığında lökosit kemotaksis ve fagositozunun engellendiği gösterilmiştir. ${ }^{[57]}$ Glukoz pro-inflamatuvar bir mediyatör gibi davranıp sitokin üretimini stimüle etmekte ve endoteliyal nitrik oksit seviyesini inhibe etmektedir. ${ }^{[66]}$ Kan glukoz seviyesi $250 \mathrm{mg} / \mathrm{dl}$ üzerine çıktığında lökosit kemotaksisi ve fagositoz engellenir. ${ }^{[57]}$

Diyabet ve hipergliseminin PPE üzerine etkisi iyi bilinse de, hangi parametrenin bu konuda direkt etkili olduğu konusu açık değildir. Diyabeti olmayan, ancak cerrahi sırasında kan glukoz seviyesi yüksek seyreden hastaların da PPE açısından yüksek risk grubuna girdikleri belirtilmektedir. Bu konudaki bir çalışmada, PPE gelişen hastalar cerrahi sırasında incelendiğinde artmış glukoz seviyeleri ile karşılaşılmış ve cerrahi sonrası sabah kan şekerinin $200 \mathrm{mg} / \mathrm{dl}$ 'nin üzerinde olduğu durumlarda PPE riskinin ikiye katlandığı belirtilmiştir. ${ }^{[67]}$ Bunun in vitro çalışmalarda gösterildiği gibi, artmış biyofilm oluşumuna ${ }^{[68]}$, bozulmuş lökosit fonksiyonuna veya mikrovasküler değişikliklere bağlı olarak gecikmiş yara iyileşmesine bağlı olabileceği düşünülmüştür.
Tablo 1. Charlson indeksine göre komorbidite değerlendirme çizelgesi

\begin{tabular}{|c|c|}
\hline Hastalık & $\begin{array}{c}\text { Komorbidite } \\
\text { puanı }\end{array}$ \\
\hline $\begin{array}{l}\text { Koroner arter hastalığı } \\
\text { Konjestif kalp yetmezlıği } \\
\text { Kronik pulmoner akciğer hastalığı } \\
\text { Peptik ülser } \\
\text { Periferik damar hastalığı } \\
\text { Serebrovasküler hastalık } \\
\text { Diabetes mellitus } \\
\text { KC hastalığı (hafif) } \\
\text { Konnektif doku hastalığı } \\
\text { Demans }\end{array}$ & 1 \\
\hline $\begin{array}{l}\text { Diabetes mellitus [uç organ hasarı }(+) \text { ] } \\
\text { Kronik renal yetmezlik } \\
\text { Hemipleji } \\
\text { Nonmetastatik solid tümör } \\
\text { Lösemi } \\
\text { Lenfoma } \\
\text { Multipl miyelom }\end{array}$ & 2 \\
\hline KC hastalığı (orta-ağır) & 3 \\
\hline $\begin{array}{l}\text { Metastatik solid tümör } \\
\text { AIDS }\end{array}$ & 6 \\
\hline
\end{tabular}

Tablo 2. Charlson indeksine göre komorbidite derecesi

\begin{tabular}{ll}
\hline Toplam puan & Komorbidite derecesi \\
\hline 0 & 0 \\
$1-2$ & $1-2$ \\
$3-4$ & $3-4$ (riskli grup) \\
5 ve üzeri & 5 ve üzeri (çok riskli grup)
\end{tabular}

Diyabetik hastalarda HbA1c seviyesi, önceki üç aylık dönemdeki ortalama serum glukoz konsantrasyonunun bir göstergesi olarak değerlendirilir. Yüksek seviyedeki HbA1c ile PPE gelişme riskinin ciddi arttığını $^{[64]}$, sıkı kontrol edilmiş HbA1c seviyesinin diyabete bağlı uzun dönem birçok komplikasyonun engellenmesinde etkili olduğunu gösteren birçok çalışma mevcuttur ${ }^{[69,70]}$. Diğer taraftan, HbA1c seviyesi ile cerrahi sonrası yüzeyel veya derin enfeksiyon gelişmesi arasında bir ilişkinin olmadığını belirten yayınlar da mevcuttur. ${ }^{[65]}$

Uzun süre kontrolsüz diyabete sahip hastalar, cerrahi öncesi ve sonrası dönemlerde, sadece cerraha değil, aynı zamanda anesteziste ve diğer ilgili klinisyenlere de ek problemler oluşturur. ${ }^{[71]}$ Bu hastalarda kollajen sentezinin daha yavaş ve yetersiz olmasından dolayı, yara yeri iyileşme problemlerine de sık rastlanır. Literatürde, $\% 12$ 'yi bulan oranlarda yara yeri problemlerine 
rastlandığı belirtilmiştir. ${ }^{[72-74]}$ Ayrıca diyabetik ayak yarası mevcudiyetinin ve periferik nöropatinin de yüksek PPE riski taşıdığı aşikardır.

Bu bilgiler ışığında, cerrahi sırasında kontrolsüz diyabeti olanların kan şeker seviyelerinin kontrol altına alınmasının, HbA1c seviyesinin mümkünse yedinin altında, kan glukozunun ise cerrahi sırasında muhakkak $200 \mathrm{mg} / \mathrm{dl}$ 'nin altında tutulmasının, PPE gelişme riskini azaltmak için önemli olduğu belirtilmelidir.

\section{Romatoid Artrit}

Total eklem replasmanı uygulanan hastaların yaklaşık \%5'ini romatoid artrit (RA) hastaları oluşturur. ${ }^{[6]}$ RA'nın PPE gelişimi için risk oluşturduğu birçok çalışmada gösterilmesine rağmen ${ }^{[39,75]}$, hangi mekanizma ile buna neden olduğu tam olarak aydınlatılamamıştır. Hastalığın tabiatının, immünsupresif tedavi rejiminin veya her ikisinin kombinasyonunun neden olabileceği ileri sürülmüştür. ${ }^{[6]} \mathrm{Bu}$ hasta grubu, hastalığın tabiatı gereği özellikle kemik eklem ve yumuşak dokular olmak üzere, tüm enfeksiyöz hastalıklara daha yatkındırlar. ${ }^{[76]}$ RA'lı hastalar cerrahi sonrası erken dönem yara komplikasyonları açısından da yüksek riske sahiptirler. ${ }^{[77]}$ Bu yatkınlık kortikosteroid veya diğer immün sistem modülatör ilaçların kullanımı ile açıklanabilir. ${ }^{[39]}$ Bu ilaçlar; NSAii'ler, kortikosteroidler, metotreksat gibi hastalık modifiye edici antiromatizmal ajanlar (DMARD), tümör nekrotizan faktör (TNF) antagonistleri veya interlökin-1 (IL-1) antagonistleridir. Bu ilaçların immün sistem üzerine supresif etkileri vardır ve bunlar patojenlere karşı hastaların savunma sistemlerini olumsuz etkiler.

S.aureus, RA'lı hastalarda PPE'den en çok sorumlu patojendir. ${ }^{[78]}$ Kombine metotrexat ve anti-TNF kullanımına bağı olarak, RA'lı hastaların orafarinks ve ciltlerinin S.aureus kolonizasyonuna daha yatkın olabileceği düşünülmüştür. ${ }^{[79]}$

Kortikosteroid kullanımının cerrahi yara enfeksiyonunu arttırabileceği bildirilse $\mathrm{de}^{[80]}$ bu konu halen tartışmalıdır. Bir çalışmada, cerrahi öncesi steroid alan hastalarda yara yeri enfeksiyon insidansının, almayanlara göre iki kat yüksek bulunduğu bildirmiştir. ${ }^{[81]}$ Ancak, bu konuda yapılan diğer çalışmalarda, cerrahi sonrası yara yeri enfeksiyonu ile streoid kullanımı arasında anlamlı bir ilişki bulunamamıştır.

Bir folat analoğu olan metotrexat RA'da en sık kullanılan DMARD'lardan birisidir. Cerrahi sırasında metotrexata ara verildiğinde daha az komplikasyonlarla karşılaşıldığını bildiren çalışmalar yanında ${ }^{[82]}$, özellikle eklem replasmanlarını içeren elektif ortopedik cerrahide, metotrexat tedavisine ara verilmeden devam edildiğinde, cerrahi sonrası bir yıllık dönemde enfeksiyon oranlarında bir artış olmadığını gösteren ileriye dönük randomize çalışmalar da mevcuttur. ${ }^{[83]}$

Anti-TNF ajanlar bu hasta grubu için standart tedavilerden biri haline gelmiştir. Ancak anti-TNF tedavisi altında iken total eklem replasmanı uygulanan RA'ı hastalarda PPE riskinin arttığı gözlenmiştir. ${ }^{[84,85]} \mathrm{Bir}$ sistematik derlemede RA tedavisinde kullanılan antiTNF antikorların hastaneye yatarak antimikrobiyal tedavi almayı gerektirecek derecede enfeksiyon riskinde artış meydana getirdiği bildirilmiştir. ${ }^{[86]} \mathrm{Bu}$ ajanların yüksek dozlarının, bu hasta grubunda ciddi enfeksiyona yol açmadığını bildiren yayınlar bulunmasına rağmen ${ }^{[87]}$, uzun dönem kullanımlarının PPE riskinde artış yapıp yapmadığı da henüz netlik kazanmamıştır.

Yukarıdaki verilen bilgiler ışığında total eklem artroplastisi yapılacak RA'lı hastalara cerrahi sırasında kullanılacak, hastalıkları ile ilgili ajanların günümüz pratiğinde protokolü şu şekilde belirlenmiştir:

- NSAii'ler 24-72 saat önce kesilir, cerrahi sonrası dönemde kanama kontrolü sonrası tekrar başlanabilir.

- Gluokortikoidler cerrahi öncesi mutad dozda kullanılabilir, ameliyat günü ve sonraki günlerde doz ayarlaması ile devam edilebilir.

- Hastalık modifiye edici ajanlar (DMARD) bir hafta önce kesilmeli, ameliyat günü kullanılmamalı, ameliyattan bir hafta sonra tekrar başlanmalıdır.

- Anti-TNF biyolojik ajanlarda, aktif metabolitlerin yarı ömrünün çok uzun olmasından dolayı tam bir görüş birliği yoktur; ancak genel kanı, cerrahiden önceki bir dozun atlanması, ameliyat günü kullanılmaması ve cerrahiden iki hafta sonra tekrar başlanması yönündedir.

- Siklosporin gibi immünsupresif ajanlara cerrahi öncesi ve sonrası mutad dozda devam edilebilir.

\section{Sistemik Malignensi}

Önceleri, sistemik malignensi varlığının PPE için risk faktörü olduğu düşünülürdü. ${ }^{[6]}$ Bunun, malignensi için kullanılan tedavilerin immünsupresif etkilerinden veya malignensinin kendisi ile ilgili bilinmeyen faktörlerden kaynaklandığı varsayılırdı. Ancak son dönem çalışmalarda, primer malignensinin veya metastatik tümörün cerrahi sonrası yara yeri enfeksiyonu ${ }^{[80]}$ ve $\mathrm{PPE}^{[4]}$ riskini arttırmayacağı bildirildi.

Literatüre bakıldığında, altta yatan malignensilere bağlı nadir görülen patojenler tarafından oluşturulmuş birçok PPE olgu sunumları mevcuttur. ${ }^{[88-91]}$ Burada neden olan mikroorganizmaların, altta yatan kolon, meme, over, mesane kanserleri gibi patolojilere 
bağlı olarak; grup D streptokoklar, Clostridium genera, Klebsiella pneumaniae, Listeria monocytogenes ve mikobakteriler olduğu görülüyordu. Bunda muhtemelen mikroorganizmaların fırsatçılıklarının yanında, konağın enfeksiyona yatkın hale gelmesinin de rolü vardı. Her ne kadar bu durumun biyolojik mekanizması ile ilgili bilgiler az ise de, bu noktada kanser ve immün sistem disfonksiyonu arasında bir ilişki olduğu görülmektedir. ${ }^{[92]}$ Bu patojenlerin çoğu intestinal kaynaklı olduğundan, maligniteye veya uygulanan antikanser tedaviye bağlı gelişen zayıflamış sistemik veya mukozal seviyedeki lokal savunma sisteminin, bozulmuş bakteriyel floradan sorumlu olması muhtemeldir. Nitekim, normalde yaygın olmayan grup D streptokokların, kolon kanserli hastaların kültüründe çok daha fazla ürediği görülmüştür. ${ }^{[93]} \mathrm{Bu}$ patojenlerin immün bariyeri bozulmuş olan mukozalardan geçerek kana karıştığı ve hematojen yolla protez etrafına yerleştiği düşünülmektedir.

\section{Malnütrisyon}

Başarılı cerrahi sonuç için, hastanın beslenme durumu önemlidir. Malnütrisyon, kollajen ve proteoglikan sentezini bozacağı için, yara iyileşmesini olumsuz etkiler. Ayrıca immün sistemin çalışmasını da bozabilir. Cerrahi sırasında beslenme bozukluğu olanlarda, artmış yara iyileşme problemleri ile karşılaşılmıştır. ${ }^{[94]}$ Malnütrisyonun bağımsız bir risk faktörü ya da sadece hastadaki komorbiditelerden birisi olup olmadığı henüz tam açıklığa kavuşmamıştır. Yetersiz beslenmesi olan artroplasti hastalarının uzun dönem PPE riskini araştıran çalışmalar halen yetersizdir.

Serum albümininin 3,5g/dl, transferrinin $200 \mathrm{mg} / \mathrm{dl}$ ve lenfositlerin milimetrede 1500 'den az olması durumunda malnütrisyondan bahsedilir. ${ }^{[94]}$ Bunlar, her ne kadar iyi belirteçler olsalar da, kalori ve vitamin eksikliği gibi malnütrisyonun diğer yönlerini göstermez.

Herhangi bir majör cerrahi sonrası rutin oluşan katabolik durum, bir de iştahsızlık ile birleşince, besin ihtiyacı daha da artar. Yeterli besin reservi, bu fizyolojik cevabın oluşturacağı yan etkileri en aza indirebilir. ${ }^{[95]}$

Malnütrisyonu olan hastada, artmış cerrahi ve anestezi zamanı, gecikmiş yara iyileşmesi, uzamış rehabilitasyon süresi, uzun hastanede kalış ve daha fazla hastane içi konsültasyon oranı tespit edilmiştir. ${ }^{[94-97]} \mathrm{Bu}$ hastalardaki suboptimal beslenmeye, yaşlanma dahil birçok altta yatan durum neden olabilir.

\section{Posttravmatik Artrit}

Posttravmatik artrit nedeniyle TKA yapılan hastalarda, primer osteoartrit nedeniyle yapılanlara göre daha yüksek PPE riski olduğu belirtilmiştir. ${ }^{[23]}$ Uzamış cerrahi süre gereksinimi, ameliyatın daha kompleks hale gelmesi, yumuşak dokuların normale göre daha düşük kalitede olması, bu durum için muhtemel nedenlerdir. Kalça kırı̆ıııın TKA yapılan hastalarda PPE için bağımsız bir risk faktörü olduğu bildirilmiştir. ${ }^{[10,23]}$ Bu durumun nedeni tam olarak bilinmemekle birlikte, artroplasti yapılacak sahada lokal doku hasarının olması ve travmaya sistemik cevabın bu hastaları enfeksiyona yatkın hale getirebileceği belirtilmektedir. Diğer muhtemel nedenler, kalça kırığı geçiren hastanın genel sağlık durumunun zayıf olması ve yeterli cerrahi öncesi hasta optimizasyonu yapılamadan cerrahi uygulanmak zorunda kalınması olabilir.

Kalçalardakine benzer şekilde, daha önce açık redüksiyon ve osteosentez geçirmiş dizlerde, özellikle de kalıntı internal tespit materyallerinin bulunmasının PPE açısından risk faktörü olduğu değerlendirilmiştir. ${ }^{[5,98]}$ Ancak geçirilmiş artroskopi ve yüksek tibial osteotominin enfeksiyon riskini arttırmadığı bildirilmiştir. ${ }^{\left[{ }^{[8]}\right.}$ Posttravmatik artrit sonrası TDA geçiren hastaların normalde artroplasti gerektiren popülasyona göre daha genç olması, ayrıca dikkate alınması gereken bir konudur.

\section{Kronik Böbrek Yetmezliği}

Kronik böbrek yetmezliği (KBY) olanlarda renal osteodistrofiye veya amiloid artropatisine bağlı osteoartrit, osteoporoz, patolojik kırıklar sık görülür. ${ }^{[99-101]}$ Dejeneratif eklem hastalığının ilerlemiş olduğu hastalar total eklem replasmanı gerektirirler. KBY'li hastalarda, genel popülasyona göre 5-6 kat daha fazla eklem replasman cerrahisine ihtiyaç duyulur. ${ }^{[102]}$ Ancak özellikle hemodiyalize bağımlı olanlarda daha fazla olmak üzere, KBY'de total eklem replasmanı ardından cerrahi sonrası komplikasyonlarla daha sık karşılaşılır. Bunun nedeninin multifaktöriyel olduğu düşünülür. $\mathrm{Bu}$ hasta grubundaki multipl kombine komorbiditeler, kollektif hareket ederek enfeksiyon riskini arttırabilir. ${ }^{[102,103]}$ Bu hasta grubu, hastaneye yatan hastalar arasında en düşkün, en problemli olanlardır ve diyaliz kateterleri nedeniyle de, enfeksiyonlara daha yatkın hale gelirler. Gerek böbrek yetmezliğine neden olan DM ve sistemik lupus eritematozus gibi altta yatan hastalıklar ve gerekse böbrek yetmezliğinin kendisi bu hastaları PPE'ye açık hale getirebilir. ${ }^{[04-106]}$ Kronik böbrek yetmezliği olan hastalarda komorbiditelere bağlı olarak ortaya çıkan metabolik imbalans, azalmış immün cevap ve tekrarlayan bakteriyemilerin, artmış enfeksiyon riskinden sorumlu diğer faktörler olduğu düşünülmektedir. ${ }^{[107]}$ Literatürü incelendiğimizde, total eklem replasmanı yapılan ve kronik böbrek yetmezliği olan hastalarda, PPE oranının \%30'lara kadar ulaştığını görebilmekteyiz. ${ }^{104,106,108,109]}$ 
Diğer taraftan, kronik böbrek yetmezliğinin PPE oranlarında artış yapmadığını bildiren az sayıda çalışma da mevcutttur. ${ }^{[110-112]}$ Ne var ki, bu serilerdeki hasta sayılarının yeterli istatistiki güce ulaşacak seviyede olmadığı görülmektedir.

\section{Kardiyovasküler Hastalıklar}

Birçok çalışma kardiyovasküler hastalıkların artroplasti hastalarını PPE'ye yatkın hale getirdiğini göstermiştir. ${ }^{[3,4,67]}$ ileri kardiyovasküler hastalığı olanlar genellikle yaşlıdırlar ve yara problemleri gelişimine yatkındırlar. ${ }^{[3]} \mathrm{Bu}$ hastalarda atriyel fibrilasyon veya miyokard enfarktüsü, yüksek enfeksiyon riski açısından önemli komorbid faktörlerdir. ${ }^{[3]}$ Geriye dönük bir çaIışmaya göre, atriyel fibrilasyonun ciddi şekilde artmış PPE'ye neden olduğu tespit edilmiştir. ${ }^{[113]} \mathrm{Bu}$ artmış enfeksiyon riskinin, büyük ihtimalle agresif antikoagülasyondan kaynaklandığı düşünülmektedir. ${ }^{[3]}$ Riski minimize etmek için kardiyovasküler hastalığı olanlarda, kardiyologlar ile temasa geçip mümkünse antikoagülan tedaviye ara verilmeli ve INR değerleri normale indirilmelidir. ${ }^{[113]}$

\section{Cerrahi Öncesi Anemi}

Elektif total eklem replasmanı yapılan hastalarda cerrahi öncesi anemi, kadınlarda hemoglobinin 12g/ dl'nin erkeklerde 13g/dl'nin altında olması, \%15-33 karşılaşılan bir durumdur. ${ }^{[114]}$ Anemik olmayanlarla kıyaslandığında (\%2), anemik hastalarda istatistiki olarak önemli derecede yüksek PPE'ye rastlandığı $(\% 4,3)$ tespit edilmiş, bu sonuca göre cerrahi öncesi aneminin bağımsız bir risk faktörü olduğu bildirilmiştir. ${ }^{[114]}$

Cerrahi öncesi anemik hastalar, cerrahi sırasında daha fazla allojenik kan transfüzyon ihtiyacı göstermekte, bu da cerrahi sonrasıenfeksiyon riskini arttırmaktadır. ${ }^{[115]}$ Bu yüzden, ortopedistlerin cerrahi öncesi anemiye neden olan Fe eksikliği gibi nedenleri araştırması ve hastayı bu açıdan optimize ettikten sonra cerrahi zamanını belirlemesi, PPE riskini azaltmak için uygun olacaktır. ${ }^{[103,116,117]}$

\section{Hemofili}

Hemofilik hastalara son dönem kronik hemofilik artropati nedeniyle, genç yaşta artroplasti uygulanması gerekebilir. ${ }^{[118,119]}$ Hemofilik hastalarda PPE oranı \%1,4-16 arasında değişen oranlarda bildirilmiştir. ${ }^{118-121]}$ Ciddi artrofibrozise, deformiteye ve kemik stok yetmezliğine bağlı cerrahinin kompleksliği kadar cerrahi sonrası yüksek oranda cerrahi saha hematomu veya hemartrozu gelişme riski, bu hasta grubunda erken cerrahi sonrası PPE riskinin artmasına yol açabilir. ${ }^{[120,121]}$ Bununla beraber, cerrahi sırasındaki bakımda gelişmeler, bu hastalarda belirgin şekilde erken cerrahi sonrası PPE gelişme riskini azaltmıştır. ${ }^{[18]}$ Aslında şu an hemofilik hastalardaki asıl sorun geç PPE'dir. ${ }^{[119,121]}$ HIV ve Hepatit $C$ kaynaklı immünsupresyon, bu hastalarda PPE'ye neden olan diğer faktördür. Bu hastalarda $\% 90$ ve $\% 70$ oranlarında 10 yıllık enfeksiyonsuz sağkalım tespit edilmiştir. [121,122]

S. epidermidis, bu hastalarda en sık karşılaşılan PPE etkenidir. ${ }^{[123]}$ En sık mekanizma ise, hastanın kendisine pıhtılaşma faktörü uygulaması esnasında, patojenin dolaşıma katılması ve hematojen yolla PPE'ye yol açması şeklindedir. ${ }^{[123]}$

\section{Orak Hücreli Anemi}

Medikal alandaki gelişmeler, orak hücreli anemisi olanların ömürlerini dramatik şekilde arttırmıştır. ${ }^{[24]}$ Bu popülasyon, daha sık kalça osteonekrozunun neden olduğu aktivite kısıtlaması ve ağrı nedeniyle, genellikle erken yaşta eklem replasmanı gerektirmektedir. TKP sonrası en yüksek komplikasyon oranına, bu hastalarda rastlandığı bildirilmiştir. ${ }^{[125]} \mathrm{Her}$ ne kadar eski küçük olgu serilerinde \%20 civarında enfeksiyon oranları bildirilse de, yakın zamandaki bir çalışma \%3 gibi çok daha düşük enfeksiyon oranını yakalayabilmiştir. ${ }^{[126]}$ Bu hastalarda PPE etkeni olarak ilk akla gelen Salmonella olsa da, halen S.aureus ve $\operatorname{Gr}(-)$ bakteriler en sık patojenlerdir. ${ }^{125,126]} \mathrm{Bu}$ hastalarda enfeksiyon riskini arttıran muhtemel nedenler; femur başı osteonekrozu, latent enfeksiyon birlikteliği, hiperplastik kemik iliğinden ameliyat sırasında artmış kan kaybı, teknik zorluk nedeniyle uzamış cerrahi zamanı ve uzun hastanede kalış süresi olarak belirlenmiştir. ${ }^{[125-128]}$

\section{Aynı Eklemde Daha Önceki Cerrahi}

Artroplasti sahasında daha önceden yapılmış cerrahi işlemlerin, hem kalça hem de dizde PPE için risk faktörü olduğu belirtilmiştir. ${ }^{[6,55,129,130]}$ Önceki cerrahiye bağlı gelişmiş skar dokuları, ameliyat süresini uzatır. ${ }^{[55]}$ Ayrıca iyi planlanmamış cilt insizyonları ve devitalize olmuş dokular da cerrahi yara komplikasyonlarına yol açarak enfeksiyon oluşturabilir. ${ }^{[131]}$

\section{S.aureus Kolonizasyonu}

Önceleri nazal S.aureus taşıyıcılığının yüzeyel yara enfeksiyonu için bir risk faktörü olduğu belirtilirdi. Nazal kavitenin vücutta en fazla S.aureusun izole edilebileceği yer olduğ $u^{[131]}$ ve buradaki taşıyıcılığın yüzeyel yara enfeksiyonu için bağımsız bir risk faktörü olduğu tespit edilmişti ${ }^{[27]}$. Bu noktada yapılan çalışmalarda, genel popülasyonun üç gruba ayrıldığı, \%20'sinin sürekli 
taşıyıcı, \%60'ının aralıklı taşıyıcı ve kalan \%20'sinin ise taşıyıcı olmadığı bulunmuştu. Günümüzde ise, ortalama S.aureus taşıyıcılığının \%37,2 civarında olduğu bilinmektedir. ${ }^{[131]}$

Son yıllarda yapılan Cochrane analizli cerrahi çalışmalarda, S.aureus taşıyıcılarına cerrahi öncesi nazal mupirosin uygulanmasının nozokomial S.aureus enfeksiyonlarda ciddi düşüşe neden olduğu, ancak yüzeyel yara yeri enfeksiyonlarında önemli bir değişiklik oluşturmadığı bildirilmişti. ${ }^{[132]}$ Fakat bu sefer de mupirosin kullanan grupta S.aureus dışındaki mikroorganizmaların yaptığı enfeksiyon oranının istatistiki olarak anlamlı derecede arttığı gözlendi. Bu da bize, floradan S.aureus yok edildiğinde yerini başka patojenlerin aldığını göstermektedir.

Diğer bazı çalışmalarda ise, cerrahi öncesi S.aureusun eradike edilmesiyle yüzeyel yara enfeksiyonunun azaldığı gösterilmektedir. ${ }^{[133,134]}$ Her ne kadar nazal S.aureus taşıyıcılığı ile yüzeyel yara enfeksiyonu arasında açık bir ilişki olduğu gösterilmişse de, bu taşıyıcılık ile PPE arasında henüz anlamlı bir ilişki kurulamamış gibi gözükmektedir.

\section{3. İlaç Kullanımı}

\section{a. Non-steroid anti-inflamatuvar ilaçlar (NSAii)}

NSAii'ler, analjezik ve anti-inflamatuvar etkilerini iki ayrı yolak üzerinden gösterir: siklooksijenaz enzimleri (COX-1, COX-2) ile prostaglandin (özellikle PGI2) ve tromboksan sentezinin inhibisyonu ve protein-protein sinyallerine aracılık ederek beyaz hücre aktivasyonunu sağlamak. ${ }^{[135]} \mathrm{Bu}$ ilaçlar, total eklem replasmanı cerrahisi sırasında ağrı tedavisinde önemli rol oynar. ${ }^{[136]}$ Platelet fonksiyonlarının üzerine olumsuz etkileri ile kanama riskini arttıracağı için, bu hastalarda NSAii'lerin kullanımı ile ilgili endişeler gündeme gelmiştir.[39] Geçmişte bu durumu destekler sonuçlar yayımlanmışsa $\mathrm{da}^{[137]}$, son dönem verileri NSAii'lerin kanama riskinde belirgin bir artış yapmadıklarını veya transfüzyon ihtiyaCı oluşturmadıklarını göstermektedir. ${ }^{[138]}$ Aynı şekilde, NSAii'lerin direkt olarak PPE riski oluşturduklarına dair bir veri yoktur. Artroplasti kayıt sistemlerine dayanarak yapılmış çalışmalarda, heterotopik ossifikasyonu engellemek için cerrahi sonrası dönemde NSAii alan hastalarla almayanlar arasında, PPE insidansı açısından bir fark bulunamamıştır. ${ }^{[13]}$

\section{b. Platelet fonksiyon inhibitörleri}

Klopidogrel, trombosit yüzeyindeki pürinerjik reseptörleri geri dönüşümsüz olarak inhibe ederek, trombosit agregasyonunu yenileri oluşuncaya kadar yaklaşık bir hafta engeller. Benzer şekilde, düşük doz aspirin de tromboxan yolağını bloke ederek, trombositleri geçici olarak inhibe eder. ${ }^{[139]}$ Trombosit inhibisyonu, kan transfüzyon ihtiyacı meydana getirecek kadar kan kaybına ve uzamış drenaj, hematom oluşumu ve enfeksiyon gibi yara yeri komplikasyonlarına yol açabilir.[140,141] $\mathrm{Ne}$ yazık ki, antiplateletlerin artroplasti hastalarında oluşturduğu PPE riski üzerine çalışmalar yok denecek kadar azdır.

Trombositlerin, lökositlerin vasküler yaralanma sahasına çekilmesi, immün cevabı düzenleyen sitokinlerin salınması, bazı antibakteriyel proteinlerin serbest bırakılması ve lenfositlerle etkileşim yolu ile antikor üretimininin arttırılması gibi önemli görevleri de vardır. ${ }^{[142,143]}$ Ancak platelet fonksiyon blokajının immün sistem üzerine klinik etkileri yeterince araştırılmamıştır. Bir geriye dönük çalışmanın sonucuna göre, klopidogrelin elektif diz ve kalça ameliyatından beş gün önce kesilmesinin daha düşük oranda enfeksiyon nedeniyle reoperasyon ve antibiyotik kullanımı sağladığı, yaradaki selüliti ve drenajı azalttığı bildirilmiştir. ${ }^{[44]}$ Aynı çalışmaya göre cerrahi sonrası klopidogrelin başlanma zamanının komplikasyonlara bir etkisinin olmadığı görülmüştür. Ancak klopidogrel kullanan bu hastalarda beklenmedik şekilde yüksek enfeksiyona (\%6) rastlandığı, bunun da klopidogrelden bağımsız multipl diğer faktörlere bağlı olabileceği belirtilmiştir.

\section{c. Antikoagülanlar}

Antikoagülasyon, artroplasti hastalarında cerrahi sonrası tromboembolik komplikasyonları azaltmak için, cerrahi sırasında takibin rutin bir komponentidir. ${ }^{[145,146]}$ Tromboembolik olayları engellemek ile potansiyel kanama komplikasyonlarına yakalanmamak arasında dikkatli bir ayar yapılması gereklidir. ${ }^{[147]}$ Ancak çalışmalar profilaktik antikoagülasyon tedavisi sırasında tek düşünülmesi gereken problemin kan kaybı olmadığını, yeterince büyük olduğunda hematomların yara problemlerine ve cilt nekrozlarına yol açabileceğini belirtmektedir. ${ }^{[148,149]}$ Bir çalışmada, TDA sonrası bir ay içinde boşaltılmayı gerektiren hematomların hematomu olmayanlarla karşılaştırıldığında, PPE riskini önemli ölçüde arttırdığı (\%10,8'e karşılık, \%0,8) tespit edilmiştir. ${ }^{[150]}$

Düşük molekül ağırlıklı heparinin enjektabl formunu kullanan hastalarda, oral warfarine göre yüksek oranlarda hemorajik komplikasyonlar rapor edilmiştir. ${ }^{[149,151]}$ Cerrahi öncesi tromboprofilaksi olarak oral warfarin kullanan hastalarla hiç profilaksi almayan hastaların karşılaştırıldığı bir çalışmada, warfarin alan grupta daha fazla oranda yüzeyel ve derin cerrahi yara enfeksiyonuna rastlanmıştır. ${ }^{[152]}$ Ayrıca INR'nin üçten yüksek olduğu durumlarda daha fazla kanama, hematom ve persistan drenaj gibi yara kaynaklı komplikasyonlarla ve PPE ile karşılaşılmıştır. ${ }^{[147,153]}$ Bu bulgular, 
antikoagülasyonun derecesi ile PPE riski arasında bariz bir ilişki olduğunu, antikoagülasyonuna dikkat edilmediği takdirde yararlı etkileri yerine zararlı bir ajana dönüşebileceğini göstermektedir.

\section{KAYNAKLAR}

1. Kurtz SM, Ong KL, Lau E, Bozic KJ, Berry D, Parvizi J. Prosthetic joint infection risk after TKA in the Medicare population. Clin Orthop Relat Res 2010;468(1):52-6. Crossref

2. Ong KL, Kurtz SM, Lau E, Bozic KJ, Berry DJ, Parvizi J. Prosthetic joint infection risk after total hip arthroplasty in the Medicare population. J Arthroplasty 2009;24(6 Suppl):105-9. Crossref

3. Pulido L, Ghanem E, Joshi A, Purtill JJ, Parvizi J. Periprosthetic joint infection: the incidence, timing, and predisposing factors. Clin Orthop Relat Res 2008;466(7):1710-5. Crossref

4. Bozic KJ, Lau E, Kurtz S, Ong K, Berry DJ. Patient-related risk factors for postoperative mortality and periprosthetic joint infection in medicare patients undergoing TKA. Clin Orthop Relat Res 2012;470(1):130-7. Crossref

5. Jämsen E, Huhtala H, Puolakka T, Moilanen T. Risk factors for infection after knee arthroplasty. A register-based analysis of 43,149 cases. J Bone Joint Surg Am 2009;91(1):38-47. Crossref

6. Berbari EF, Hanssen AD, Duffy MC, Steckelberg JM, Ilstrup DM, Harmsen WS, Osmon DR. Risk factors for prosthetic joint infection: case control study. Clin Infect Dis 1998;27(5):1247-54.

7. Aggarwal VK, Tischler EH, Lautenbach C, Williams GR, Abboud JA, Altena M, Bradbury TL, Calhoun JH, Dennis DA, Del Gaizo DJ, Font-Vizcarra L, Huotari K, Kates SL, Koo KH, Mabry TM, Moucha CS, Palacio JC, Peel TN, Poolman RW, Robb WJ 3rd, Salvagno R, Seyler T, Skaliczki G, Vasarhelyi EM, Watters WC 3rd. Mitigation and education. J Arthroplasty 2014;29(2 Suppl):19-25. Crossref

8. Kurtz SM, Lau E, Schmier J, Ong KL, Zhao K, Parvizi J. Infection burden for hip and knee arthroplasty in the United States. J Arthroplasty 2008;23(7):984-91. Crossref

9. Soohoo NF, Farng E, Lieberman JR, Chambers L, Zingmond DS. Factors that predict short-term complication rates after total hip arthroplasty. Clin Orthop Relat Res 2010;468(9):2363-71. Crossref

10. Ridgeway S, Wilson J, Charlet A, Kafatos G, Pearson A, Coello R. Infection of the surgical site after arthroplasty of the hip. J Bone Joint Surg Br 2005;87(6):844-50.

11. Dale H, Skråmm I, Løwer HL, Eriksen HM, Espehaug B, Furnes O, Skjeldestad FE, Havelin LI, Engesaeter LB. Infection after primary hip arthroplasty: a comparison of 3 Norwegian health registers. Acta Orthop 2011;82(6):646-54. Crossref

12. Robertsson O, Knutson K, Lewold S, Lidgren L. The Swedish Knee Arthroplasty Register 1975-1997: an update with special emphasis on 41,223 knees operated on in 1988-1997. Acta Orthop Scand 2001;72(5):503-13.

13. Pedersen AB, Svendsson JE, Johnsen SP, Riis A, Overgaard $S$. Risk factors for revision due to infection after primary total hip arthroplasty. A population-based study of 80,756 primary procedures in the Danish Hip Arthroplasty Registry. Acta Orthop 2010;81(5):542-7. Crossref

14. Tosi LL, Boyan BD, Boskey AL. Does sex matter in musculoskeletal health? The influence of sex and gender on musculoskeletal health. J Bone Joint Surg Am 2005;87(7):1631-47.
15. Mahomed NN, Barrett J, Katz JN, Baron JA, Wright J, Losina E. Epidemiology of total knee replacement in the United States Medicare population. J Bone Joint Surg Am 2005;87(6):1222-8.

16. Lübbeke A, Stern R, Garavaglia G, Zurcher L, Hoffmeyer P. Differences in outcomes of obese women and men undergoing primary total hiparthroplasty. Arthritis Rheum 2007;57(2):327-34.

17. Willis-Owen CA, Konyves A, Martin DK. Factors affecting the incidence of infection in hip and knee replacement: an analysis of 5277 cases. J Bone Joint Surg Br 2010;92(8):112833. Crossref

18. Kim M-K, Patel RA, Shinn AH, Choi SY, Byun HJ, Huh $\mathrm{CH}$, Park KC, Youn SW. Evaluation of gender difference in skin type and pH. J Dermatol Sci 2006;41(2):153-6.

19. Fierer N, Hamady M, Lauber CL, Knight R. The infl uence of sex, handedness, and washing on the diversity of hand surface bacteria. Proc Natl Acad Sci USA 2008;105(46):17994-9. Crossref

20. Larsson I, Bertéus Forslund $\mathrm{H}$, Lindroos AK, Lissner L, Näslund I, Peltonen M, Sjöström L. Body composition in the SOS (Swedish Obese Subjects) reference study. Int J Obes Relat Metab Disord 2004;28(10):1317-24.

21. Herwaldt LA, Cullen JJ, French P, Hu J, Pfaller MA, Wenzel RP, Perl TM. Preoperative risk factors for nasal carriage of Staphylococcus aureus. Infect Control Hosp Epidemiol 2004;25(6):481-4.

22. SooHoo NF, Lieberman JR, Ko CY, Zingmond DS. Factors predicting complication rates following total knee replacement. J Bone Joint Surg Am 2006;88(3):480-5.

23. Cordero-Ampuero J, Esteban J, García-Rey E. Results after late polymicrobial, gram-negative, and methicillin-resistant infections in knee arthroplasty. Clin Orthop Relat Res 2010;468(5):1229-36. Crossref

24. Malchau H, Herberts P, Eisler T, Garellick G, Söderman P. The Swedish Total Hip Replacement Register. J Bone Joint Surg Am 2002;84-A Suppl 2:2-20.

25. Chesney D, Sales J, Elton R, Brenkel IJ. Infectionafter knee arthroplasty a prospective study of 1509 cases. J Arthroplasty 2008;23(3):355-9. Crossref

26. Jämsen E, Nevalainen $P$, Kalliovalkama J, Moilanen $T$. Preoperative hyperglycemia predicts infected total knee replacement. EurJ Intern Med 2010;21(3):196-201. Crossref

27. Kalmeijer MD, van Nieuwland-Bollen E, Bogaers-Hofman D, de Baere GA. Nasal carriage of Staphylococcus aureus is a major risk factor for surgical-site infections in orthopedic surgery. Infect Control Hosp Epidemiol 2000;21(5):319-23.

28. Namba RS, Inacio MC, Paxton EW. Risk factors associated with deep surgical site infections after primary total knee arthroplasty: an analysis of 56,216 knees. J Bone Joint Surg Am 2013;95(9):775-82. Crossref

29. Malinzak RA, Ritter MA, Berend ME, Meding JB, Olberding EM, Davis KE. Morbidly obese, diabetic, younger, and unilateral joint arthroplasty patients have elevated total joint arthroplasty infection rates. J Arthroplasty 2009;24(6 Suppl):84-8. Crossref

30. Dowsey MM, Choong PF. Obese diabetic patients are at substantial risk for deep infection after primary TKA. Clin Orthop Relat Res 2009;467(6):1577-81. Crossref

31. Peel TN, Dowsey MM, Daffy JR, Stanley PA, Choong PF, Buising KL. Risk factors for prosthetic hip and knee infections according to arthroplasty site. J Hosp Infect 2011;79(2):12933. Crossref 
32. Gandhi R, Razak F, Davey JR, Mahomed NN. Metabolic syndrome and the functional outcomes of hip and knee arthroplasty. J Rheumatol 2010;37(9):1917-22. Crossref

33. Dy CJ, Wilkinson JD, Tamariz L, Scully SP. Influence of preoperative cardiovascular risk factor clusters on complications of total joint arthroplasty. Am J Orthop (Belle Mead NJ) 2011;40(11):560-5.

34. Namba RS, Paxton L, Fithian DC, Stone ML. Obesity and perioperative morbidity in total hip and total knee arthroplasty patients. J Arthroplasty 2005;20 (7 Suppl 3):46-50.

35. Winiarsky $R$, Barth $P$, Lotke P. Total knee arthroplasty in morbidly obese patients. J Bone Joint Surg Am 1998;80(12):1770-4.

36. Guss D, Bhattacharyya T. Perioperative management of the obese orthopaedic patient. J Am Acad Orthop Surg 2006;14(7):425-32.

37. Patel VP, Walsh M, Sehgal B, Preston C, DeWal H, Di Cesare $\mathrm{PE}$. Factors associated with prolonged wound drainage after primary total hip and knee arthroplasty. J Bone Joint Surg Am 2007;89(1):33-8.

38. Hopf HW, Hunt TK, West JM, Blomquist P, Goodson WH 3rd, Jensen JA, Jonsson K, Paty PB, Rabkin JM, Upton RA, von Smitten K, Whitney JD. Wound tissue oxygen tension predicts the risk of wound infection in surgical patients. Arch Surg 1997; 132(9):997-1004.

39. Moucha CS, Clyburn T, Evans RP, Prokuski L. Modifiable risk factors for surgical site infection. J Bone Joint Surg Am 2011;93(4):398-404.

40. Berbari EF, Osmon DR, Lahr B, Eckel-Passow JE, Tsaras G, Hanssen AD, Mabry T, Steckelberg J, Thompson R. The Mayo prosthetic joint infection risk score: implication for surgical site infection reporting and risk stratification. Infect Control Hosp Epidemiol 2012;33(8):774-81. Crossref

41. Jorgensen LN, Kallehave F, Christensen E, Siana JE, Gottrup F. Less collagen production in smokers. Surgery 1998;123(4):450-5.

42. Glassman SD, Anagnost SC, Parker A, Burke D, Johnson JR, Dimar JR. The effect of cigarette smoking and smoking cessation on spinal fusion. Spine (Phila Pa 1976) 2000;25(20):2608-15.

43. Sørensen LT, Jørgensen $S$, Petersen LJ, Hemmingsen $U$, Bülow J, Loft S, Gottrup F. Acute effects of nicotine and smoking on blood flow, tissue oxygen, and aerobe metabolism of the skin and subcutis. J Surg Res 2009;152(2):224-30. Crossref

44. Møller AM, Villebro N, Pedersen T, Tønnesen H. Effect of preoperative smoking intervention on postoperative complications: a randomised clinical trial. Lancet 2002;359(9301):114-7.

45. Thomsen T, Villebro N, Møller AM. Interventions for preoperative smoking cessation. Cochrane Database Syst Rev 2010;(7):CD002294. Crossref

46. Khan LAK, Cowie JG, Ballantyne JA, Brenkel IJ. The complication rate and medium-term functional outcome after total hip replacement in smokers. Hip Int 2009;19(1):47-51.

47. Tønnesen H, Nielsen PR, Lauritzen JB, Møller AM. Smoking and alcohol intervention before surgery: evidence for best practice. Br J Anaesth 2009;102(3):297-306. Crossref

48. Harris AH, Reeder R, Ellerbe L, Bradley KA, Rubinsky AD, Giori NJ. Preoperative alcohol screening scores: association with complications in men undergoing total joint arthroplasty. J Bone Joint Surg Am 2011;93(4):321-7. Crossref
49. Bradley KA, Rubinsky AD, Sun $H$, Bryson CL, Bishop MJ, Blough DK, Henderson WG, Maynard C, Hawn MT, Tønnesen $\mathrm{H}$, Hughes G, Beste LA, Harris AH, Hawkins EJ, Houston TK, Kivlahan DR. Alcohol screening and risk of postoperative complications in male VA patients undergoing major noncardiac surgery. J Gen Intern Med 2011;26(2):162-9. Crossref

50. Tønnesen $\mathrm{H}$. Alcohol abuse and postoperative morbidity. Dan Med Bull 2003;50:139-60.

51. Tonnesen $H$, Rosenberg J, Nielsen HJ, Rasmussen $V$, Hauge $C$, Pedersen IK, Kehlet $\mathrm{H}$. Effect of preoperative abstinence on poor postoperative outcome in alcohol misusers: randomised controlled trial. BMJ 1999;318(7194):1311-6.

52. Zeidel A, Beilin B, Yardeni I, Mayburd E, Smirnov G, Bessler $\mathrm{H}$. Immune response in asymptomatic smokers. Acta Anaesthesiol Scand 2002;46:959-64.

53. Whiteford L. Nicotine, $\mathrm{CO}$ and $\mathrm{HCN}$. the detrimental effects of smoking on wound healing. $\mathrm{Br} J$ Community Nurs 2003;8(12):S22-6.

54. Rezapoor M, Parvizi J. Prevention of Periprosthetic Joint Infection. J Arthroplasty 2015;30(6):902-7. Crossref

55. Peersman G, Laskin R, Davis J, Peterson M. Infection in total knee replacement: a retrospective review of 6489 total knee replacements. Clin Orthop Relat Res 2001;(392):15-23.

56. Fletcher $\mathrm{N}$, Sofianos $\mathrm{D}$, Berkes MB, Obremskey WT. Prevention of perioperative infection. J Bone Joint Surg Am 2007;89(7):1605-18.

57. Lai K, Bohm ER, Burnell C, Hedden DR. Presence of medical comorbidities in patients with infected primary hip or knee arthroplasties. J Arthroplasty 2007;22(5):651-6.

58. Charlson ME, Pompei P, Ales KL, MacKenzie CR. A new method of classifying prognostic comorbidity in longitudinal studies: development and validation. J Chronic Dis 1987;40(5):373-83.

59. National Nosocomial Infections Surveillance System. National Nosocomial Infections Surveillance (NNIS) System Report, data summary from January 1992 through June 2004, issued October 2004. Am J Infect Control 2004;32(8):470-85.

60. Mak PH, Campbell RC, Irwin MG; American Society of Anesthesiologists. The ASA Physical Status Classification: interobserver consistency. American Society of Anesthesiologists. Anaesth Intensive Care 2002;30(5):633-40.

61. Salemi C, Anderson D, Flores D. American Society of Anesthesiology scoring discrepancies affecting the National Nosocomial Infection Surveillance System: surgical-siteinfection risk index rates. Infect Control Hosp Epidemiol 1997;18(4):246-7.

62. Culver DH, Horan TC, Gaynes RP, Martone WJ, Jarvis WR, Emori TG, Banerjee SN, Edwards JR, Tolson JS, Henderson TS, et al. Surgical wound infection rates by wound class, operative procedure, and patient risk index. National Nosocomial Infections Surveillance System. Am J Med 1991;91(3B):152S-157S.

63. Cazanave C, Greenwood-Quaintance KE, Hanssen AD, Karau MJ, Schmidt SM, Gomez Urena EO, Mandrekar JN, Osmon DR, Lough LE, Pritt BS, Steckelberg JM, Patel R. Rapid molecular microbiologic diagnosis of prosthetic joint infection. J Clin Microbiol 2013;51(7):2280-7. Crossref

64. Marchant MH, Viens NA, Cook C, Vail TP, Bolognesi MP. The impact of glycemic control and diabetes mellitus on perioperative outcomes after total joint arthroplasty. J Bone Joint Surg Am 2009;91(7):1621-9. Crossref

65. Iorio R, Williams KM, Marcantonio AJ, Specht LM, Tilzey JF, Healy WL. Diabetes mellitus, hemoglobin A1C, and the incidence of total joint arthroplasty infection. J Arthroplasty 2012;27(5):726-9.e1. Crossref 
66. Dronge AS, Perkal MF, Kancir S, Concato J, Aslan M, Rosenthal RA. Long-term glycemic control and postoperative infectious complications. Arch Surg 2006;141(4):375-80.

67. Mraovic B, Suh D, Jacovides C, Parvizi J. Perioperative hyperglycemia and postoperative infection after lower limb arthroplasty. J Diabetes Sci Technol 2011;5(2):412-8.

68. Seneviratne CJ, Yip JW, Chang JW, Zhang CF, Samaranayake LP. Effect of culture media and nutrients on biofilm growth kinetics of laboratory and clinical strains of Enterococcus faecalis. Arch Oral Biol 2013;58(10):1327-34. Crossref

69. Anon. Intensive blood-glucose control with sulphonylureas or insulin compared with conventional treatment and risk of complications in patients with type 2 diabetes (UKPDS 33). UK Prospective Diabetes Study (UKPDS) Group. Lancet 1998;352(9131):837-53.

70. Anon. The effect of intensive treatment of diabetes on the development and progression of long-term complications in insulin-dependent diabetes mellitus. The Diabetes Control and Complications Trial Research Group. N Engl J Med 1993;329(14):977-86.

71. Burgos LG, Ebert TJ, Asiddao C, Turner LA, Pattison CZ, Wang-Cheng R, Kampine JP. Increased intraoperative cardiovascular morbidity in diabetics with autonomic neuropathy. Anesthesiology 1989;70(4):591-7.

72. Yang K, Yeo SJ, Lee BP, Lo NN. Total knee arthroplasty in diabetic patients: a study of 109 consecutive cases. J Arthroplasty 2001;16(1):102-6.

73. Serna F, Mont MA, Krackow KA, Hungerford DS. Total knee arthroplasty in diabetic patients. Comparison to a matched control group. J Arthroplasty 1994;9(4):375-9.

74. England SP, Stern SH, Insall JN, Windsor RE. Total knee arthroplasty in diabetes mellitus. Clin Orthop Relat Res 1990;(260):130-4.

75. Bongartz T, Halligan CS, Osmon DR, Reinalda MS, Bamlet WR, Crowson CS, Hanssen AD, Matteson EL. Incidence and risk factors of prosthetic joint infection after total hip or knee replacement in patients with rheumatoid arthritis. Arthritis Rheum 2008;59(12):1713-20. Crossref

76. Doran MF, Crowson CS, Pond GR, O'Fallon WM, Gabriel SE. Frequency of infection in patients with rheumatoid arthritis compared with controls: a population-based study. Arthritis Rheum 2002;46(9):2287-93.

77. White RH, McCurdy SA, Marder RA. Early morbidity after total hip replacement: rheumatoid arthritis versus osteoarthritis. J Gen Intern Med 1990;5(4):304-9.

78. Berbari EF, Osmon DR, Duffy MC, Harmssen RN, Mandrekar JN, Hanssen AD, Steckelberg JM. Outcome of prosthetic joint infection in patients with rheumatoid arthritis: the impact of medical and surgical therapy in 200 episodes. Clin Infect Dis 2006;42(2):216-23.

79. Bassetti S, Wasmer S, Hasler P, Vogt T, Nogarth D, Frei R, Widmer AF. Staphylococcus aureus in patients with rheumatoid arthritis under conventional and antitumor necrosis factor-alpha treatment. J Rheumatol 2005;32(11):2125-9.

80. Malone DL, Genuit T, Tracy JK, Gannon C, Napolitano LM. Surgical site infections: reanalysis of risk factors. J Surg Res 2002;103(1):89-95.

81. Post $S$, Betzler $M$, von Ditfurth B, Schürmann G, Küppers $P$, Herfarth C. Risks of intestinal anastomoses in Crohn's disease. Ann Surg 1991;213(1):37-42.

82. Howe CR, Gardner GC, Kadel NJ. Perioperative medication management for the patient with rheumatoid arthritis. J Am Acad Orthop Surg 2006;14(9):544-51.
83. Grennan D, Gray J, Loudon J, Fear S. Methotrexate and early postoperative complications in patients with rheumatoid arthritis undergoing elective orthopaedic surgery. Ann Rheum Dis 2001;60(3):214-7.

84. Momohara S, Kawakami K, Iwamoto T, Yano K, Sakuma Y, Hiroshima R, Imamura H, Masuda I, Tokita A, Ikari K. Prosthetic joint infection after total hip or knee arthroplasty in rheumatoid arthritis patients treated with nonbiologic and biologic disease-modifying antirheumatic drugs. Mod Rheumatol 2011;21(5):469-75. Crossref

85. Giles JT, Bartlett SJ, Gelber AC, Nanda S, Fontaine K, Ruffing $\mathrm{V}$, Bathon JM. Tumor necrosis factor inhibitor therapy and risk of serious postoperative orthopedic infection in rheumatoid arthritis. Arthritis Rheum 2006;55(2):333-7.

86. Bongartz T, Sutton AJ, Sweeting MJ, Buchan I, Matteson EL, Montori V. Anti-TNF antibody therapy in rheumatoid arthritis and the risk of serious infections and malignancies: systematic review and meta-analysis of rare harmful effects in randomized controlled trials. JAMA 2006;295(19):2275-85.

87. Zintzaras E, Dahabreh IJ, Giannouli S, Voulgarelis M, Moutsopoulos HM. Infliximab and methotrexate in the treatment of rheumatoid arthritis: a systematic review and meta-analysis of dosage regimens. Clin Ther 2008;30(11):1939-55. Crossref

88. Liddle AD, Abram S, lyer S, Andrade AJ. Streptococcus gallolyticus prosthetic joint infection associated with undiagnosed colonic malignancy. Knee Surg Sports Traumatol Arthrosc 2012;20(6):1069-70. Crossref

89. Chougle A, Narayanaswamy V. Delayed presentation of prosthetic joint infection due to Listeria monocytogenes. Int J Clin Pract 2004;58(4):420-1.

90. Morshed S, Malek F, Silverstein RM, O'Donnell RJ. Clostridium cadaveris septic arthritis after total hip arthroplasty in a metastatic breast cancer patient. J Arthroplasty 2007;22(2):289-92.

91. Chodos MD, Johnson CA. Hematogenous infection of a total knee arthroplasty with Klebsiella pneumoniae in association with occult adenocarcinoma of the cecum. J Arthroplasty 2009;24(1):158. Crossref

92. Finn OJ. Immune response as a biomarker for cancer detection and a lot more. N Engl J Med 2005;353(12):1288-90.

93. Klein RS, Recco RA, Catalano MT, Edberg SC, Casey JI, Steigbigel NH. Association of Streptococcus bovis with carcinoma of the colon. N Engl J Med 1977;297(15):800-2.

94. Greene KA, Wilde AH, Stulberg BN. Preoperative nutritional status of total joint patients. Relationship to postoperative wound complications. J Arthroplasty 1991;6(4):321-5.

95. Lavernia CJ, Sierra RJ, Baerga L. Nutritional parameters and short term outcome in arthroplasty. J Am Coll Nutr 1999;18(3):274-8.

96. Gherini S, Vaughn BK, Lombardi AV Jr, Mallory TH. Delayed wound healing and nutritional defi ciencies after total hip arthroplasty. Clin Orthop Relat Res 1993;(293):188-95.

97. Marín LA, Salido JA, López A, Silva A. Preoperative nutritional evaluation as a prognostic tool for wound healing. Acta Orthop Scand 2002;73(1):2-5.

98. Suzuki G, Saito S, Ishii T, Motojima S, Tokuhashi Y, Ryu J. Previous fracture surgery is a major risk factor of infection after total knee arthroplasty. Knee Surg Sports Traumatol Arthrosc 2011;19(12):2040-4. Crossref

99. Brown EA, Arnold DL, Cower PE. Dialysis arthropathy: complication of long term treatment with haemodialysis. $\mathrm{Br}$ Med J (Clin Res Ed) 1986;292(6514):163-6. 
100. Ford PM. Arthropathies associated with renal disease including dialysis-related amyloid. Curr Opin Rheumatol 1992;4(1):63-7.

101. Sakabe $T$, Imai $R$, Murata $H$, Fujioka $M$, Ivamoto $N$, Ono $\mathrm{T}$, Kubo T. Life expectancy and functional prognosis after femoral neck fractures in hemodialysis patients. J Orthop Trauma 2006;20(5):330-6.

102. Lieu D, Harris IA, Naylor JM, Mittal R. Review article: Total hip replacement in haemodialysis or renal transplant patients. J Orthop Surg (Hong Kong) 2014;22(3):393-8.

103. Baek SH. Identification and preoperative optimization of risk factors to prevent periprosthetic joint infection. World J Orthop 2014;5(3):362-7. Crossref

104. Lieberman JR, Fuchs MD, Haas SB, Garvin KL, Goldstock L, Gupta R, Pellicci PM, Salvati EA. Hip arthroplasty in patients with chronic renal failure. J Arthroplasty 1995;10(2):191-5.

105. Sakalkale DP, HozackWJ, Rothman RH. Total hip arthroplasty in patients on long-term renal dialysis. J Arthroplasty 1999;14(5):571-5.

106. Sunday JM, Guille JT, Torg JS. Complications of joint arthroplasty in patients with end-stage renal disease on hemodialysis. Clin Orthop 2002;(397):350-5.

107. Naito M, Ogata K, Shiota E, Nakamoto M, Goya T. Hip arthroplasty in haemodialysis patients. J Bone Joint Surg $\mathrm{Br}$ 1994;76(3):428-31.

108. Shrader MW, Schal D, Parvizi J, McCarthy JT, Lewallen DG. Total hip arthroplasty in patients with renal failure: a comparison between transplant and dialysis patients. J Arthroplasty 2006;21(3):324-9.

109. McCleery MA, Leach WJ, Norwood T. Rates of infection and revision in patients with renal disease undergoing total knee replacement in Scotland. J Bone Joint Surg Br 2010;92(11):1535-9. Crossref

110. Nagoya S, Nagao M, Takada J, Kuwabara H, Kaya M, Yamashita T. Efficacy of cementless total hip arthroplasty in patients on long-term hemodialysis. J Arthroplasty 2005;20(1):66-71.

111. Toomey HE, Toomey SD. Hip arthroplasty in chronic dialysis patients. J Arthroplasty 1998;13(6):647-52.

112. Li WC, Shih $\mathrm{CH}$, Ueng SW, Shih HN, Lee MS, Hsieh PH. Uncemented total hip arthroplasty in chronic hemodialysis patients. Acta Orthop 2010;81(2):178-82. Crossref

113. Aggarwal VK, Tischler EH, Post ZD, Kane I, Orozco FR, Ong A. Patients with atrial fibrillation undergoing total joint arthroplasty increase hospital burden. J Bone Joint Surg Am 2013;95(17):1606-11. Crossref

114. Greenky M, Gandhi K, Pulido L, Restrepo C, Parvizi J. Preoperative anemia in total joint arthroplasty: is it associated with periprosthetic joint infection? Clin Orthop Relat Res 2012;470(10):2695-701. Crossref

115. Borghi B, Casati A. Incidence and risk factors for allogenic blood transfusion during major joint replacement using an integrated autotransfusion regimen. The Rizzoli Study Group on Orthopaedic Anaesthesia. Eur J Anaesthesiol 2000;17(7):411-7.

116. Spahn DR. Anemia and patient blood management in hip and knee surgery: a systematic review of the literature. Anesthesiology 2010;113(2):482-95. Crossref

117. Myers E, O'Grady P, Dolan AM. The influence of preclinical anaemia on outcome following total hip replacement. Arch Orthop Trauma Surg 2004;124(10):699-701.

118. Goddard NJ, Mann HA, Lee CA. Total knee replacement in patients with end-stage haemophilic arthropathy: 25-year results. J Bone Joint Surg Br 2010;92(8):1085-9. Crossref
119. Rodriguez-Merchan EC, Gomez-Cardero P, Jimenez-Yuste $V$. Infection after total knee arthroplasty in haemophilic arthropathy with special emphasis on late infection. Haemophilia 2011;17(5):e831-2. Crossref

120. Chiang CC, Chen PQ, Shen MC, Tsai W. Total knee arthroplasty for severe haemophilic arthropathy: long-term experience in Taiwan. Haemophilia 2008;14(4):828-34. Crossref

121. Silva M, Luck JV Jr. Long-term results of primary total knee replacement in patients with hemophilia. J Bone Joint Surg Am 2005;87(1):85-91.

122. Zingg PO, Fucentese SF, Lutz W, Brand B, Mamisch N, Koch PP. Haemophilic knee arthropathy: long-term outcome after total knee replacement. Knee Surg Sports Traumatol Arthrosc 2012;20(12):2465-70. Crossref

123. Norian JM, Ries MD, Karp S, Hambleton J. Total knee arthroplasty in hemophilic arthropathy. J Bone Joint Surg Am 2002;84-A(7):1138-41.

124. Hagar W, Vichinsky E. Advances in clinical research in sickle cell disease. Br J Haematol 2008;141(3):346-56. Crossref

125. Vichinsky EP, Neumayr LD, Haberkern C, Earles AN, Eckman J, Koshy M, Black DM. The perioperative complication rate of orthopedic surgery in sickle cell disease: report of the National Sickle Cell Surgery Study Group. Am J Hematol 1999;62(3):129-38

126. Hernigou $P$, Zilber S, Filippini $P$, Mathieu G, Poignard A, Galacteros F. Total THA in adult osteonecrosis related to sickle cell disease. Clin Orthop Relat Res 2008;466(2):300-8. Crossref

127. Kamble S, Telen MJ, Dinan MA, Grussemeyer CA, Reed SD. Costs and length of stay for patients with and without sickle cell disease after hysterectomy, appendectomy, or knee replacement. Am J Hematol 2010;85(1):79-81. Crossref

128. Jeong GK, Ruchelsman DE, Jazrawi LM, Jaffe WL. Total hip arthroplasty in sickle cell hemoglobinopathies. J Am Acad Orthop Surg 2005;13(3):208-17.

129. Wroblewski BM, Siney PD, Fleming PA. Charnley lowfrictional torque arthroplasty in patients under the age of 51 years. Follow-up to 33 years. J Bone Joint Surg Br 2002;84(4):540-3.

130. Wilson MG, Kelley K, Thornhill TS. Infection as a complication of total knee-replacement arthroplasty. Risk factors and treatment in sixty-seven cases. J Bone Joint Surg Am 1990;72(6):878-83.

131. Kluytmans J, Van Belkum A, Verbrugh $H$. Nasal carriage of Staphylococcus aureus: epidemiology, underlying mechanisms, and associated risks. Clin Microbiol Rev 1997;10(3):505-20.

132. van Rijen $M$, Bonten $M$, Wenzel $R$, Kluytmans J. Mupirocin ointment for preventing Staphylococcus aureus infections in nasal carriers. Cochrane Database Syst Rev 2008;(4):CD006216. Crossref

133. Trautmann M, Stecher J, Hemmer W, Luz K, Panknin HT. Intranasal mupirocin prophylaxis in elective surgery. A review of published studies. Chemotherapy 2008;54(1):9-16.

134. Rao N, Cannella BA, Crossett LS, Yates AJ Jr, McGough RL 3rd, Hamilton CW. Preoperative screening/decolonization for Staphylococcus aureus to prevent orthopedic surgical site infection: prospective cohort study with 2-year follow-up. J Arthroplasty 2011;26(8):1501-7. Crossref

135. Abramson S, Weissmann G. The mechanisms of action of nonsteroidal antiinfl ammatory drugs. Clin Exp Rheumatol 1989;7 Suppl 3:S163-70. 
136. Guth AA, Hofstetter SR, Pachter HL. Human immunodeficiency virus and the trauma patient: factors influencing postoperative infectious complications. J Trauma 1996;41(2):251-5.

137. Robinson CM, Christie J, Malcolm-Smith N. Nonsteroidal antiinflammatory drugs, perioperative blood loss, and transfusion requirements in elective hip arthroplasty. J Arthroplasty 1993;8(6):607-10.

138. Parvizi J, Miller AG, Gandhi K. Multimodal pain management after total joint arthroplasty. J Bone Joint Surg Am 2011;93(11):1075-84. Crossref

139. Patrono C, García Rodríguez LA, Landolfi R, Baigent C. Lowdose aspirin for the prevention of atherothrombosis. N Engl J Med 2005;353(22):2373-83.

140. Blasco-Colmenares E, Perl TM, Guallar E, Baumgartner WA, Conte JV, Alejo D, Pastor-Barriuso R, Sharrett AR, Faraday N. Aspirin plus clopidogrel and risk of infection after coronary artery bypass surgery. Arch Intern Med 2009;169(8):788-96. Crossref

141. Biancari F, Airaksinen KE, Lip GY. Benefits and risks of using clopidogrel before coronary artery bypass surgery: systematic review and meta-analysis of randomized trials and observational studies. J Thorac Cardiovasc Surg 2012;143(3):665-75. Crossref

142. Klinger $\mathrm{MH}$, Jelkmann W. Role of blood platelets in infection and inflammation. J Interferon Cytokine Res 2002;22(9):913-22.

143. von Hundelshausen $P$, Weber $C$. Platelets as immune cells: bridging inflammation and cardiovascular disease. Circ Res 2007;100(1):27-40.

144. Nandi S, Aghazadeh M, Talmo C, Robbins C, Bono J. Perioperative clopidogrel and postoperative events after hip and knee arthroplasties. Clin Orthop Relat Res 2012;470(5):1436-41. Crossref

145. Haas SB, Barrack RL, Westrich G. Venous thromboembolic disease after total hip and knee arthroplasty. Instr Course Lect 2009;58:781-93.
146. Douketis JD, Eikelboom JW, Quinlan DJ, Willan AR, Crowther MA. Short-duration prophylaxis against venous thromboembolism after total hip or knee replacement: a metaanalysis of prospective studies investigating symptomatic outcomes. Arch Intern Med 2002;162(13):1465-71.

147. Parvizi J, Ghanem E, Joshi A, Sharkey PF, Hozack WJ, Rothman RH. Does "excessive" anticoagulation predispose to periprosthetic infection? J Arthroplasty 2007;22(6 Suppl 2):24-8.

148. Stern SH, Wixson RL, O'Connor D. Evaluation of the safety and efficacy of enoxaparin and warfarin for prevention of deep vein thrombosis after total knee arthroplasty. J Arthroplasty 2000;15(2):153-8.

149. Fitzgerald RH Jr, Spiro TE, Trowbridge AA, Gardiner GA Jr, Whitsett TL, O'Connell MB, Ohar JA, Young TR; Enoxaparin Clinical Trial Group. Prevention of venous thromboembolic disease following primary total knee arthroplasty. A randomized, multicenter, open-label, parallel-group comparison of enoxaparin and warfarin. J Bone Joint Surg Am 2001;83-A(6):900-6.

150. Galat DD, McGovern SC, Hanssen AD, Larson DR, Harrington $J R$, Clarke HD. Early return to surgery for evacuation of a postoperative hematoma after primary total knee arthroplasty. J Bone Joint Surg Am 2008;90(11):2331-6. Crossref

151. Colwell Jr CW, Collis DK, Paulson R, McCutchen JW, Bigler GT, Lutz S, Hardwick ME. Comparison of enoxaparin and warfarin for the prevention of venous thromboembolic disease after total hip arthroplasty. Evaluation during hospitalization and three months after discharge. J Bone Joint Surg Am 1999;81(7):932-40.

152. Sachs RA, Smith JH, Kuney M, Paxton L. Does anticoagulation do more harm than good?: A comparison of patients treated without prophylaxis and patients treated with lowdose warfarin after total knee arthroplasty. J Arthroplasty 2003;18(4):389-95.

153. Minnema B, Vearncombe $M$, Augustin A, Gollish J, Simor AE. Risk factors for surgical-site infection following primary total knee arthroplasty. Infect Control Hosp Epidemiol 2004;25(6):477-80. 